\title{
Analysis of the Difficulties Learning Speaking Skills at Madrasah Tsanawiyah Students Riyadlatul Ulum Batanghari East Lampung
}

\author{
Abdul Halim¹, Masrurotul Mahmudah², Muhammad Syaifullah', \\ Ikhwan Aziz $\mathbf{Q}^{4}$, Hernisawati ${ }^{5}$ \\ ${ }^{1}$ SD NU Metro, ${ }^{2 / 3 / 4 / 5}$ Institut Agama Islam Ma'arif NU Metro Lampung \\ mahmudahmasrurotul1@gmail.com
}

\author{
\begin{tabular}{l|l|l} 
Received: 05-01-2020 & Revised: 10-01-2021 & Accepted: 31-01-2021
\end{tabular}
}

\begin{abstract}
There are several factors that are very influential in language, namely human cleverness in speaking skills, Maharah al-Kalam is the ability to express articulated sounds or words to express thoughts in the form of ideas, opinions, desires, or feelings to the interlocutor. In a broader sense, speaking is a system of signs that can be heard and seen which utilizes a number of muscles and muscle tissues of the human body to convey thoughts in order to fulfill their needs. In general, maharah al-kalam aims to be able to communicate properly and properly with the language they are learning. Moving on from the problem of learning disabilities that have a big impact on learning can certainly harm teachers and students in receiving the material. In learning Arabic, of course, you really need a lot of training to speak and memorize vocabulary so that there are no difficulties in learning Arabic. Students must also be active in learning. After that the student looked difficult when he spoke Arabic and spoke it and the accuracy of Arabic was not good, Apart from memorizing habitual vocabulary by the student, creating a supportive environment for practicing conversation. With a good language environment, speech can also be intertwined well. Regardless, there are many problems in learning to speak at MTs Riyadlatul ulum which make the lack of maximum learning in speaking skills, students' lack of speaking in speaking and speaking habits can also hinder the learning process to speak, unclear pronunciation and tarkibnya arrangement make the speaker and listener make it difficult. The population in this study were students of class VIII MTs Riyadlatul Ulum, using qualitative descriptive research. Data collection was carried out by means of interviews, observation and documentation. In the interview, to find out the problems that students have experienced and to get data about the factors that influence it, in the researchers' observations the researchers looked at the problems that appeared to students when in learning and documentation for evidence of research implementation.
\end{abstract}

Keywords: Speaking Skill; The Difficulties Learning

$$
\begin{aligned}
& \text { ملخص } \\
& \text { العامل الأكثر تأثيرا في اللغة هو قدرة البشر على أن يكونوا ماهرين في التحدث، إن مهارة الكلام هي القدرة }
\end{aligned}
$$

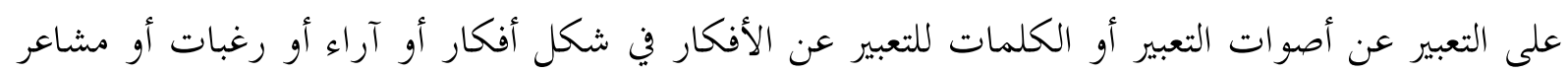

$$
\begin{aligned}
& \text { للشخص الآخر. بالمعنى الأوسع، التحدث هو نظام من العلامات التي يمكن سماعها ورؤيتها والتي تستخدم عددًا } \\
& \text { من العضلات والأنسجة العضلية للجسم البشري لتوصيل الأفكار من أجل تلبية احتياجاهم. بشكل عام، يهدف }
\end{aligned}
$$

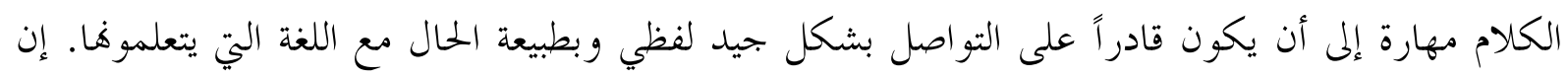

$$
\begin{aligned}
& \text { الانتقال من مشكلة صعوبات التعلم التي ها تأثير كبير على التعلم يمكن بالتأكيد أن يعرض المعلمين والطلاب } \\
& \text { للخطر في تلقي المو اد. في تعلم اللغة العربية، بالطبع، تحتاج حقًا إلى الكثير من التدريب للتحدث وحفظ المفردات } \\
& \text { بحيث لا توجد صعوبات في تعلم اللغة العربية. يجب أن يكون الطلاب أيضًا نشطين في التعلم. بعد الطالب يبدو } \\
& \text { من الصعب عندما يتحدث اللغة العربية ويتحدث وتكون دقة اللغة العربية ليست جيدة، بالإضافة إلى حفظ }
\end{aligned}
$$


عادات المفردات من قبل الطلاب، و خلق بيئة داعمة لممارسة المحادثة. مع وجود بيئة لغوية جيدة ، يمكن أيضًا تشابك الكام جيدًا. بصر ف النظر عن ذلك، هناك العديد من المشكلات في تعلم التحدث في مدرسة رياضة العلم الثّانويّة الإسلامية، مما يجعل عدم وجود أقصى قدر من التعلم في مهارات التحدث، ونقص الطلاب الذين يتحدثون في الكلام وعادات التحدث يمكن أن يعوق عملية تعلم الكام، وقلة الوضوح في النطق والتأليف بتعل المتحدث و المتكلم يصعب. السكان في هذه الدراسة هم طلاب الفصل الثامن مدرسة رياضة العلوم الثّانويّة الإسلامية بباتانج هاري لامبونج الشّرقية، مستخدمين بحثًا وصفيًا نوعيًا. يتم جمع البيانات عن طريق المقابلة و الملاحظة والوثائق. في المقابلة لمعرفة المشكلات التي واجهها الطلاب والحصول على بيانات حول العوامل التي تؤثر عليها، في ملاحظة الباحثين، يرى الباحثون المشاكل التي تظهر للطلاب أثناء التعلم والتوثيق لإثبات تنفيذ

الكلمات المفتاحية: مهارة الكام؛ صعوبات التعلم

() 2021 Abdul Halim, Masrurotul Mahmudah, Muhammad Syaifullah, Ikhwan Aziz Q, Hernisawati (c) (i) (2)

This work is licensed under a Creative Commons Attribution-ShareAlike 4.0 International License.

المقدمة

اللغة هي أحد الجوانب التى لا يمكن فصلها عن الحياة الإنسانية، لذلك يمكن القول أن اللغة هي ملك لإنسان الذي إتخد مع المالك، ثم اللغة تظهر دائما في جوانب و أنشطه الرجل وليس هناك نشاط بشري واحد لا يرافقه اللغة. في لغة الإحساس تكون أصوات الحروف المتحر كة المستخدمة في الكالام أو الرموز الخاصة بكتابات أصوات الحرووف المتحر كة، أدوات التو اصل المستخدمة في بعض المحموعات الإنسانية، حسن السلوك، حسن. وقال سونزونو داردجويدجو إن اللغة هي نظام رمزي تعسفي يستخدمة أعضاء بحتمع لعوي اللتواصل و التفاعل فيما بينهم على أسس الثقافة التى يتشار كوها.' احبو العرب لثلاث: لأنى اعرابى والقران عربى و كلام اهل الجنة عربى (رواه مسلم) '. من المعلومات الواردة أعلاه، يضع الباحث الأولوية في مهارات التحدث لدى طلاب المدرسة الثنوية منحاض العلوم تحليل عامل الصعوبة في تعلم اللغة العربية على مهارات التحدث لدى الطلاب. 'م الم بالمعنى الأوسع، التحدث هو نظام من العلامات التي يمكن سماعها ورؤيتها باستخدام عدد من العضلات والأنسجة العضلية في جسم الإنسان لنقل الأفكار من أجل تلبية احتياجاتم. قدف مهارات

${ }^{1}$ Azwar Arsyad, Bahasa Arab dan Metode Pengajarannya, (Yogyakarta: Pustaka Pelajar, 2010), hlm. 20 129

${ }^{2}$ Acep Hermawan, Metodologi Pembelajaran Bahasa Arab, (Bandung: PT Remaja Rosdakarya, 2014), hlm

${ }^{3}$ Acep Hermawan, Metodologi Pembelajaran Bahasa Arab,.. hlm 136. 
التحدث بشكل عام إلى تمكين الطلاب من التواصل بشكل جيد ومنطق إلى حد ما مع اللغة التي يتعلموها إلى جانب مهارات التحدث، هناك العديد من العوامل التي تسبب صعوبات للطلاب في تعلم

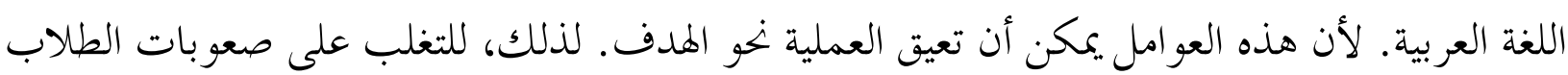
في تعلم اللغة العربية، يجب على المعلم محاولة إيجاد العوامل التي تسبب صعوبات الطلاب في اللغة العربية. صعو بات التعلم الخاصة هي اضطرابات في واحدة أو أكثر من العمليات النفسية التي هي يشمل

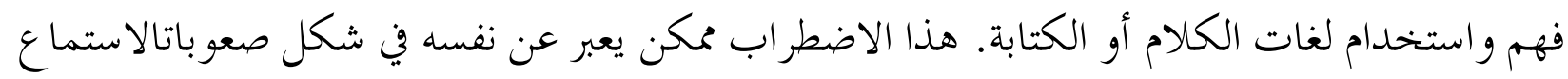

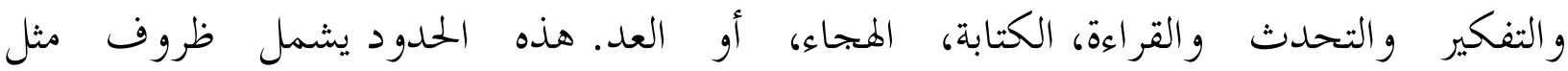
الضوضاء الإدراك الحسي، إصابة الدماغ، عسر القراءة، فقدان القدرة على الكلام التطورات. هذه الحمدود لا تغطي الأطفال الذين لديهم مشاكل في التعلم السبب الرئيسي يأتي من العقبات في الرؤية،

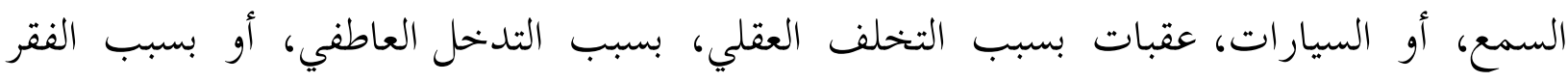
البيئي، الثقافة، أو الاقتصاد. الابتعاد عن مشكلة صعوبات التعلم التي لها تأثير كبير على التعلم يمكن أن يضر بالتأكيد المعلمين

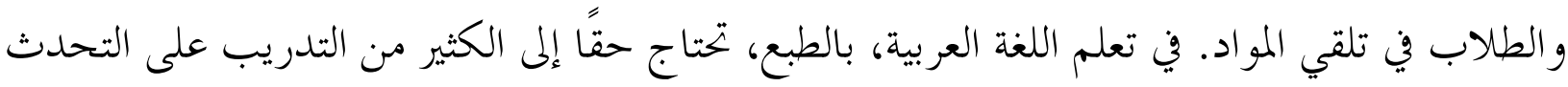

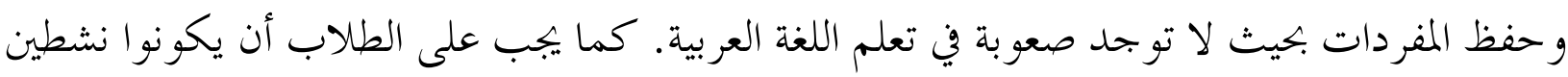
في التعلم؟ و حعظ بصرف النظر عن حفظ عادات المفردات من قبل الطلاب، وخلق بيئة داعمة لممارسة المحادثة. مع وجود بيئة لغوية جيدة، يمكن أيضًا تشابك الكلام جيدًا. بصرف النظر عن ذلك، هناك العديد من

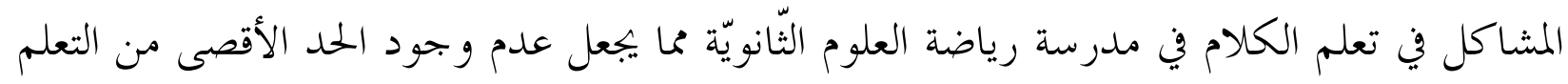
في مهار ات الكلام، ونقص الطلاب الناطقين في التحدث وعادات التحدث يمكن أن تعوق أيضا عملية التعلم في الكلام، كما أن دقة الطرق التي يستخدمها المعلم يمكن أيضا عامل في مشكلة صعوبة تعلم مهار ات الكلام. تعلم مهارات الكلام هو أحد المهارات اللغوية التي لها غرض مثير للاهتمام للطلاب ليتمكنوا من

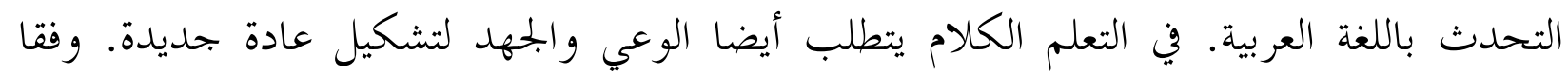

${ }^{4}$ Hasil wawancara dengan siswa (Adi Rismawan, Ahmad, Fauzan, Ramdo) di MTs Riyadlatul Ulum pada hari rabu tanggal 09 Oktober 2020 pukul 09.00 
42 Abdul Halim, Masrurotul Mahmudah, Muhammad Syaifullah, dkk: Analysis of the Difficulties Learning...

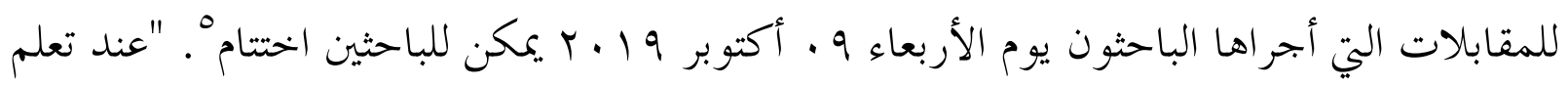
اللغات الأجنبية، يجب أن يكون لدى الطلاب أرواح إبداعية في شحذ الأحاديث حتى يتم التواصل

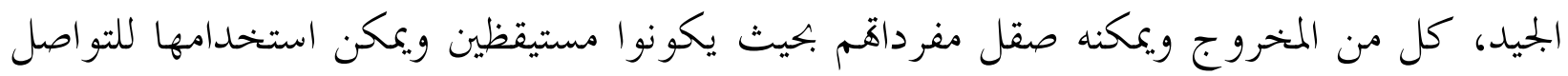

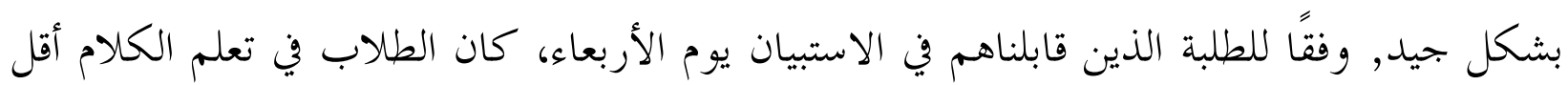
اهتمامًا بالتعلم بالإضافة إلى إيلاء اهتمام أقل للمعلمين عند حدوث التهائ التعلم وأن جو بيئة التعلم كان أقل برودة لتعلم الكلام. لا يفهم الطلاب معنى الكلمات المنطوقة. من الخلفية السابقة التي تشرح حول تعلم اللغة العربية وتحدث الكتيرامبيان بحيث يقوم الباحثون بلقب "تحليل صعو بات التعلّم لمهارة الكلام" لدى تلاميذ الفصل الثامن بمدرسة رياضة العلوم الثّانويّة بباتانج هاري لامبونج الشّرقية هدف هذه الدراسة إلى تحديد نقطة المسئلة الطلبة في تعلم التحدث باتل باللغة العربية في المدراسة. كان نوع هذا البحث من البحث الكيفي الميداني.

$$
\text { فنائج البحث ومناقشتها }
$$

صعو بات التعلم الخاصة هي اضطرابات في و احدة أو أكثر من العمليات النفسية التي هي يشمل

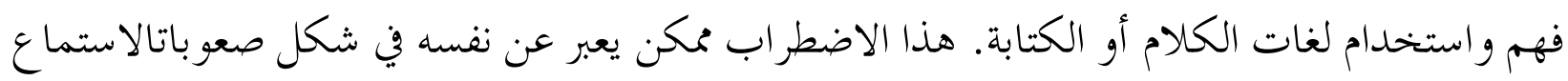

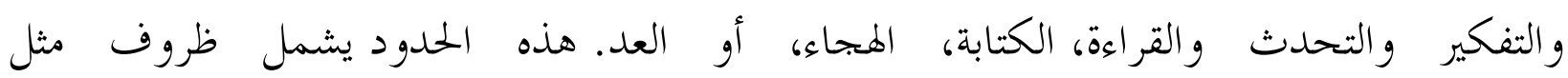
الضوضاء الإدراك الحسي، إصابة الدماغ، عسر القراءة، فقدان القدرة على الكلام التطورات. هذه الحدود لا تغطي الأطفال الذين لديهم مشاكل في التعلم السبب الرئيسي يأتي من العقبات في الرؤية،

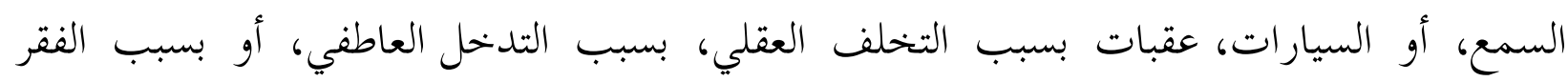
البيئي، الثقافة، أو الاقتصاد.

وبالتالي فإن الو اقع الذي نواجهه في كثير من الأحيان في كل طالب في الحياة اليومية فيما يتعلق بأنشطة التعلم. كل فرد في الواقع ليس هو نفسه. هذه الفروق الفردية تسبب أيضًا اختلافات في سلوك

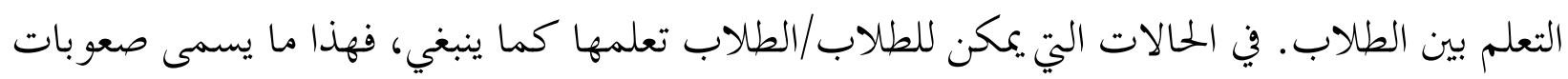
التعلم.

${ }^{5}$ Hasil wawancara dengan siswa (Adi Rismawan, Ahmad, Fauzan, Ramdo) di MTs Riyadlatul Ulum pada hari rabu tanggal 09 Oktober 2020 pukul 09.00 
لا تنجم صعوبات التعلم دائمًا عن ضعف الذكاء (الاضطر ابات العقلية)، ولكن يمكن أن

يكون سببها أيضًا عو امل غير ذكائية. وبالتالي، فإن الذكاء العالي لا يضمن بالضرورة بخاح التعلم. من أجل توفير التوجيه المناسب لكل طالب، يحتاج المعلمون إلى فهم المشكلات المرتبطة بصعوبات التعلم. العو امل التي تؤثر على التعلّم

يعد تغيير السلوك أحد أهداف التعلم، ولكن هناك العديد من العوامل التي تؤثر على صعوبات

$$
\begin{aligned}
& \text { التعلم. العوامل التي تؤثر على صعوبة التعلم هي من نوعين هما: } \\
& \text { أ) عوامل التعلم الداخلية }
\end{aligned}
$$

العوامل الداخلية هي العوامل التي تأتي من داخل الفرد نفسه، على سبيل المثال النضج والذكاء

و التحفيز و الاهتمام.

ب) عو امل التعلم الخارجي

ترتبط العوامل الخارجية ارتباطًا وثيقًا بالعوامل الاجتماعية أو البيئية للفرد المعين. على

سبيل المثال حالة البيئة الأسرية والبيئة البحتمعية والمدرسين والوسائل التعليمية المستخدمة في

$$
\text { المدر سة. }
$$

يمكن تقسيم هذه الأنواع من صعوبات التعلم إلى أربعة أنواع، على النحو التالي ج

ا ـ ينظر من نوع صعوبات التعلم

r ب ـ ينظر من بحال الدراسة التي تمت دراستها

ب. مينظر من طبيعة الصعوبة

ـ ـ من حيث العوامل التي تسبب ذلك.

مهارة الكالام

وتعرف القدرة على استخدام اللغة في عالم تدريس اللغة بالمهارات اللغوية المهارات هي واحدة

منهم يتحدث (مهارة الكالام). يتم تصنيف مهارات الكالام إلى مهارات إنتاجية (المهارة الانتجائية/المهارات الإنتاجية). لذلك، قبل أن نناقش حول مهارة الكالام، نعرف أولاً معنى كل كلمة.

أ). مفهوم المهارة الكالام

${ }^{6}$ Abu Ahmadi dan Widodo Supriyono, psikologi Belajar, cet.ke-3, (Jakarta: PT Rineka Cipta, 2013), hlm. 78

\footnotetext{
${ }^{7}$ Acep Hermawan, Metodologi Pembelajaran Bahasa Arab, (Bandung PT Remaja Rosdakarya, 2014), hlm.
} 
44 Abdul Halim, Masrurotul Mahmudah, Muhammad Syaifullah, dkk: Analysis of the Difficulties Learning...

$$
\text { مهار ات الكالام (مهرة الكالام/مهارات التحدث) هي القدرة على التعبير عن أصوات أو }
$$

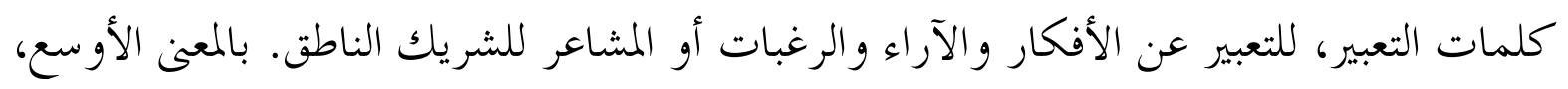

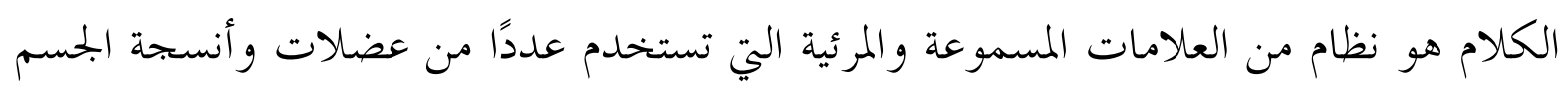

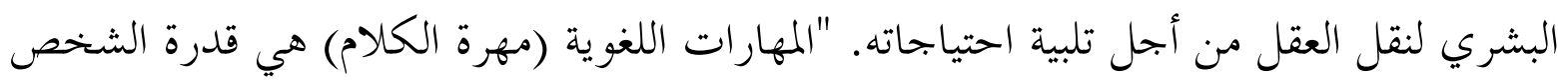

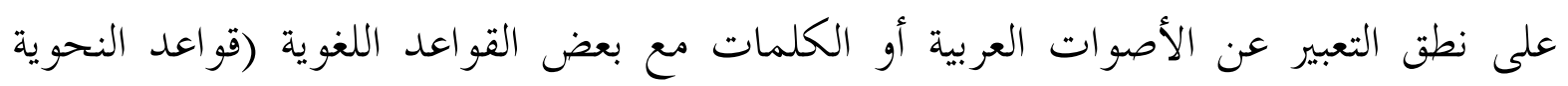

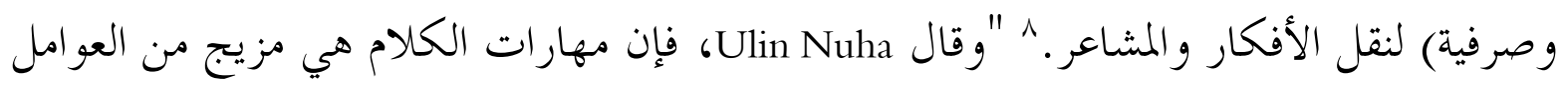
الجسدية و النفسية و العصبية والدلالية واللغوية على نطاق واسع. بحيث يمكن اعتبارها أهم أداة إنسانية للسيطرة الاجتماعية

يمكن تعلم كلام أساساً إلى نوعين، بمعنى كلام هو الحوار أو الخحادثه (الحوار و كلام في

معنى monolog شص في الأهداف التعليمية العامة الكلام للمتعلمين لديه القدرة على تكوين الجملة المثالية وفقا لقواعد اللغة العربية بشكل صحيح، وقادر على اختيار الكلمات المناسبة والسياقية

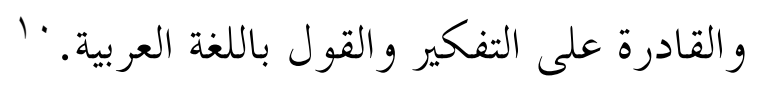

مهارة الكلام هي واحدة من المهار ات في اللغة العربية بالإضافة إلى قراءة، و كتابه، وإستماع،

حيث يرتبط كل منهم ببعضهم البعض باللغة العربية. وقال fairus zabadi في القاموس - محيط المطرة اشتقاقي مهارة، مع العلم بعمق. بالإضافة إلى ذلك، يؤ كد أحمد زكي شوليه أن مصطلح مهارا

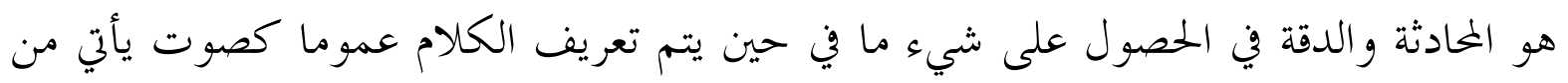

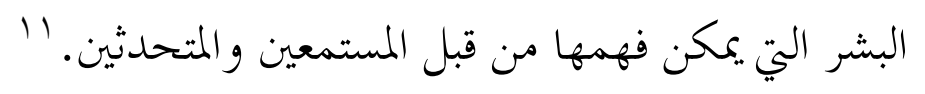

استناداً إلى بعض التفسيرات المذكورة أعلاه، يمكن أن نخلص إلى أن المهارة الكلام واحدة

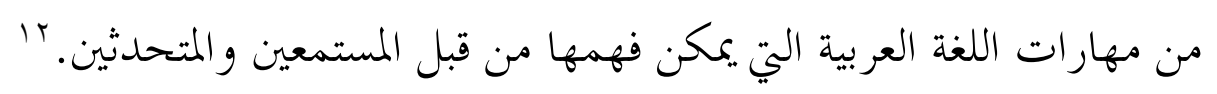

${ }^{8}$ Rahmaini, Strategi Pembelajaran Maharah Kalam Bagi Non Arab, , إحياء العربية, Medan: Fakultas Tarbiyah

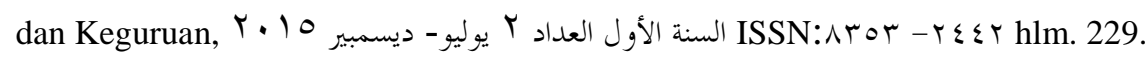

${ }^{9}$ Ulin Nuha, Metodologi Super Efektif Pembelajaran Bahasa Arab, (Jogjakarta: DIVA Press, 2012), hlm. 99.

${ }^{10}$ Munir, Perencanaan Sistem Pengajaran Bahasa Arab, (Jakarta: Kencana, 2017), hlm. 40-41.

${ }^{11}$ Ifi Erwhintiana, et al, Analisis Diagnostik Kesulitan Belajar Maharah Kalam Mahasiswa Bahasa Dan Sastra Arab 2017 Dalam Perspektifedwin R. Guthrie, HMJ Jurusan Sastra Arab Fakultas Sastra Universitas Negeri Malang, ISSN 2598-0637, tahun 2017, hlm. 109.

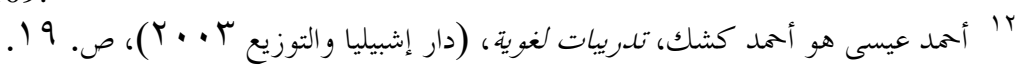


و المتأمل في برامج تعليم اللغات الأجنبية أو أدلة المعلمين المصاحبة لكتب ومناهج تعليم هذه اللغات يجدها تحدد المهارات اللغوية الواجب تعليمها للدارسين في كل مرحلة من مراحل

تعليم اللغة. وتبدو الصيغة الإجرائية في تحديد المهارات اللغوية في كثير من البرامج والأدلة' .

طبيعة عملية الكلام

الكلام مهارة انتاجية تتطلب من المتعلم القدرة على استخدام الأصوات بدقة، والتمكن من الصيغ النحوية ونظام ترتيب الكلمات التي تساعد على التعبير عما يريد أن يقوله في مو اقف الحديث،

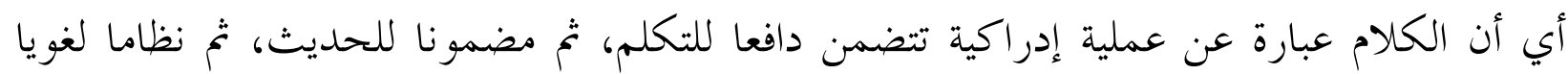
بو ساطته يترجم الدافع والمضمون في شكل كلام، و كل هذه العمليات لا يمكن ملاحظتها فهي عمليات

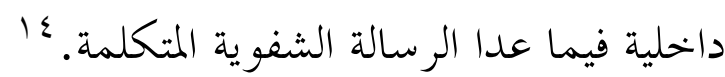

المؤشّر ات في مهارة الكلام

هناك إشارة مهارة الكلام التي تناسب بأهداف عامة لتعليم الكلام يمكن أن نعرض لأ همها فيما يلي 10

ا أن ينطق المتعلم أصوات اللغة العربية، وأن يودي أنواع التعبير والتنغيم المختلفة وذلك بطريقة مقبولة من أبناء العربية.

r أن يعبر عن أفكاره مستخدما الصيغ النحوية المناسبة بكنه r أن يستخدم بعض خصائص اللغة في التعبير الشفوي مثل التكثير والتأنيث وتمييز العدد والحال و ونظام الفعل وأزمنته و غير ذلك منما يلزم المتكلم بالعربية.

ع أن يكتسب ثروة لفظية كلامية مناسبة لعمره ومستوى تضجه وقدراته، وأن يستخدم هذه الثروة في إتمام عمليات اتصال عصربة.

ه أن يتمكن من التفكير باللغة العربية والتحدث هـا بشكل متصل ومترابط لفترات زمنية مقبولة

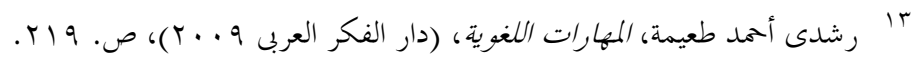

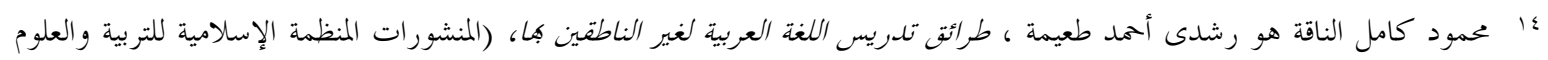

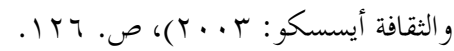

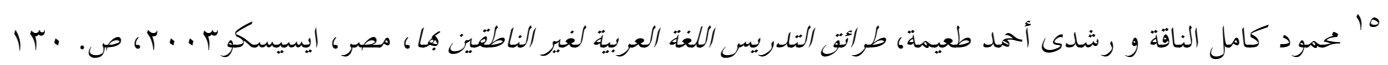


اعتمادا إلى الرأي السابق أن الهدف في تعليم الكالام هو أن يقدر الدارس في النطق عن آراءه و أفكاره طلاقة و فصيحة و صحيحة.

$$
\text { أهداف مهارات اللغة }
$$

سيتم وصف المثال التالي على صيغة موضوعية محددة وعلاقتها بعملية التعلم في الفصل. ا ) الاجتماع الأول: يتمكن المتعلدون من التعبير جريدًا عن حروف المعرفة وأحرف أ-ي. ب) الاجتماع الثاين: المتعلمين قادرين على فهم و استخدام عدد الفرية، وعدد الإسماعيلية، و الاستفهامية. ب) الاجتماع الثالث: يستطيع المتعلمون استخدام بعض المفردات (على سبيل المثال عشر كلمات) ذات صلة بالأنشطة اليومية في عدد الإسماعيلية وعدد الألفاظ وعدد من الإشتفائية. المثال عن الأنشطة في المطبخ، في الحمام، في غرفة المعيشة، و غير ذلك. ع) الاجتماع الرابع: يستطيع المتعلمون استخدام بعض المفردات (مثل عشرة أسماء) المرتبطة بالأنشطة اليومية في عدد الأسامية. 17

0) الاجتماع الخامس: يستطيع المتعلمون استخدام بعض المفردات (مثل عشرة أفعال وعشرة أسماء) المرتبطة بالأنشطة اليومية في عدد المدارس في الإسماعيلية وعدد الأوائل وعدد من الإشتفائية. هناك عدة خطو ات يمكن أن يستخدمها المعلم عند تدريس مهارات التحدث، .ما في ذلك: أ) ألمتعلمين المبتدئين (Mubtadi)

(أ) يبدأ المعلم في محارسة المحادثة من خلال تقديم الأسئلة التي يجب أن يجيب عليها الطلاب. (ب) في الوقت نفسه، يُطلب من الطلاب تعلم كيفية نطق الكلمات وترتيب الجمل و التعبير عن

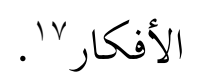
(ج) يطلب المعلم من الطلاب الإجابة على ممارسات الشافعية، أو حفظ المحادثات أو الإجابة عن الأسئلة المتعلقة بمحتوى النص الذي قرأه الطلاب تمبـ.

$$
\begin{array}{r}
\text { ب) للمتعلمين المتقدمين (المتو اضع) تعلم التحدث مع لعب الأدوار } \\
\text { (ب) ناقش الموضوع) }
\end{array}
$$

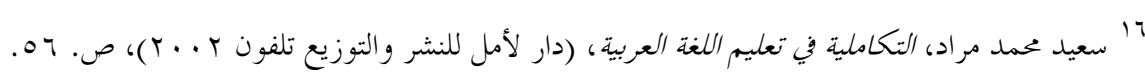

${ }^{17}$ Kuswoyo, Konsep Dasar Pembelajaran Mahārah Al-Kalam, An-Nuha :Sekolah Tinggi Agama Islam Nahdlatul Ulama, MadiunVol 4, No 1, Juli 2017, hlm. 8. 


$$
\begin{aligned}
& \text { (ج) أخبر القصص عن الأحداث التي يمر هـا الطلاب } \\
& \text { (د) يخبر عن المعلومات التي سمعت من التلفزيون أو الراديو أو غيرها. } \\
& \text { ت) للمتعلمين المتقدمين (Mutaqaddim) }
\end{aligned}
$$

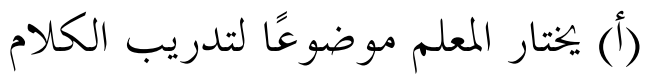

(ب) يجب أن يكون الموضوع المختار مثيرًا للاهتمام فيما يتعلق بالحياة الطلابية.$$
\text { (ج) يجب أن تكون المظاهر واضحة ومحدودة }
$$

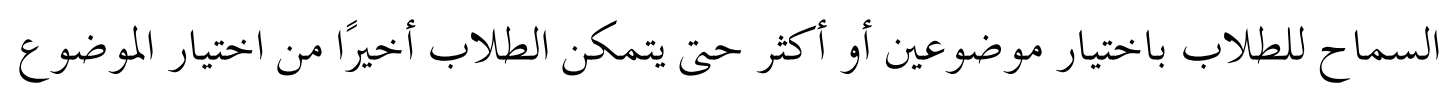

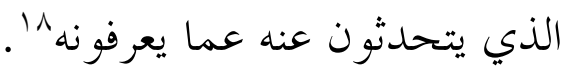

$$
\begin{aligned}
& \text { ح) مبادئ ماهاء الكلام }
\end{aligned}
$$

لكي يكون الطلاب جيدين لغير العرب، من المهم ملاحظة ما يلي:

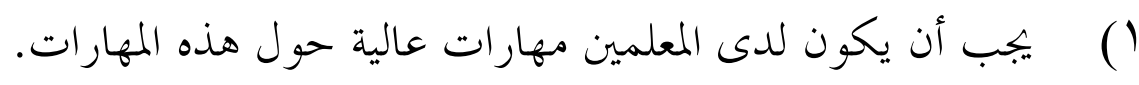

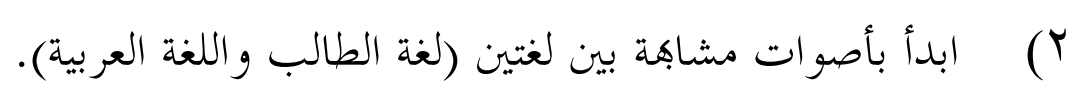

ץ) بيجب على المؤلفين و الطلاب الانتباه إلى المر احل في تدريس الكلام، مثل البدء بسهول سهلة تتألف من جملة واحدة، جملتين وما إلى ذلك.

$$
\begin{aligned}
& \text { ع) ابدأ بمفردات سهلة. }
\end{aligned}
$$

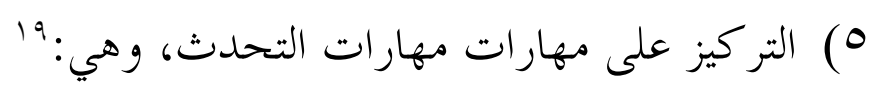

$$
\begin{aligned}
& \text { (أ) طريقة نطق الصوت من سيده بشكل صحيح وصحيح. } \\
& \text { (ب) تمييز نطق حر كات الطويلة والطويلة. }
\end{aligned}
$$

(ج) التعبير عن الأفكار بالطريقة الصحيحة من خلال مر اعاة القواعد النحوية الحالية.

$$
\text { (د) تدريب الطلاب على كيفية بدء المحادثة و إفائها بشكل صحيح. }
$$

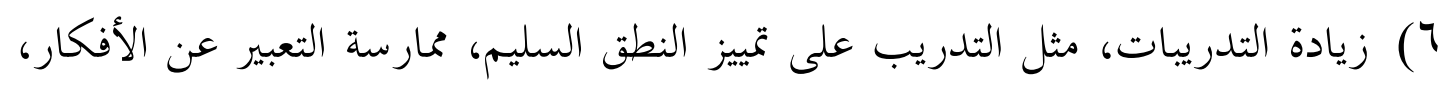

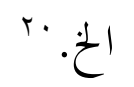

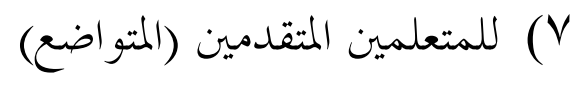

$$
\begin{aligned}
& \text { ^) تعلم التحدث عن طريق لعب الأدوار }
\end{aligned}
$$

\footnotetext{
${ }^{18}$ Kuswoyo, Konsep Dasar Pembelajaran Mahārah Al-Kalam,.. hlm. 8.

${ }^{19}$ Kuswoyo, Konsep Dasar Pembelajaran Mahārah Al-Kalam,.. hlm. 9

${ }^{20}$ Kuswoyo, Konsep Dasar Pembelajaran Mahārah Al-Kalam,.. hlm. 10
} 
48 Abdul Halim, Masrurotul Mahmudah, Muhammad Syaifullah, dkk: Analysis of the Difficulties Learning...

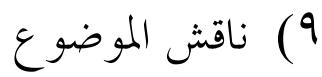

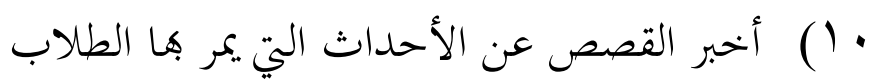

$$
\begin{aligned}
& \text { 1) (1) يخبر عن المعلومات التي سمعت من التلفزيون أو الر اديو أو غيرها. }
\end{aligned}
$$

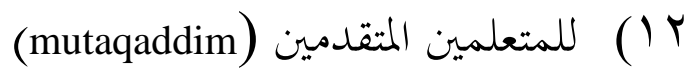

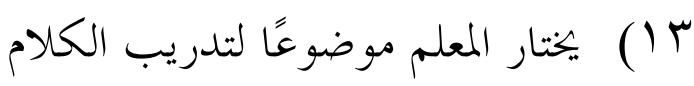

$$
\begin{aligned}
& \text { ع ( ) يجب أن يكون الموضوع المختار مثيرًا للاهتمام فيما يتعلق بالحياة الطلابية. } \\
& \text { 10 ) يجب أن تكون المظاهر واضحة ومحدودة } \\
& \text { 1 (1) السماح للطلاب باختيار موضوعين أو أكثر حتى يتمكن الطلاب أخيرًا من اختيار }
\end{aligned}
$$

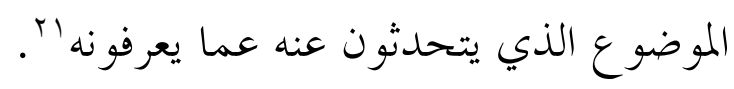

$$
\begin{aligned}
& \text { عرض بيانات البحث عن صعوبات الكلام العربي }
\end{aligned}
$$

كان عرص بيانات البحث عن صعوبات الكلام العربي هنا معتمدا على حاصلات البحث التي

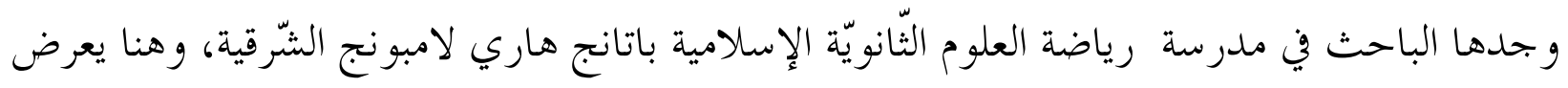

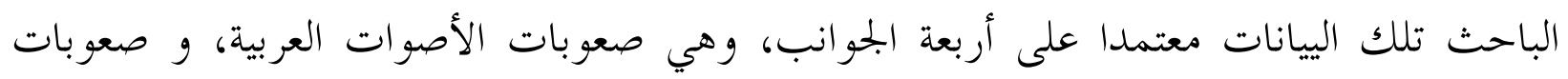

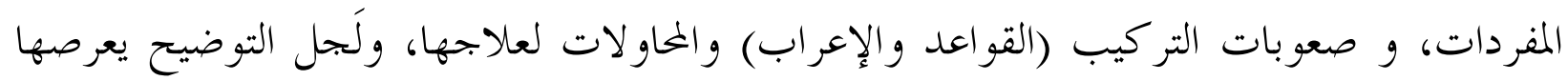

$$
\text { الباحث بالمر اتب التالية: }
$$

ترجع صعوبات الأصوات العربية إلى صعوبة التلاميذ في إصدرا الَصوات اللازمت للككلام

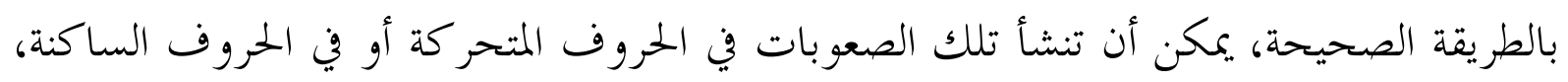
أو بسبب اختلاف الحروف الساكنة بين العربية والإندونسية، و كذا كثرة الحروف العربية التي لها

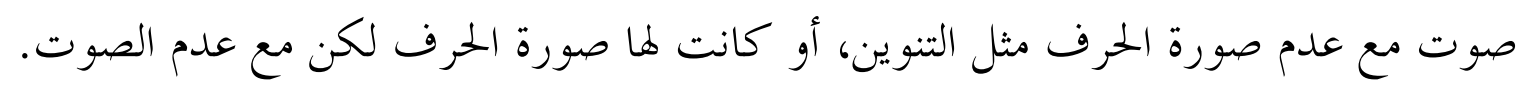
ظهرت صعوبات الأصوات العربية لدى التلاميذ من صعوباهم في نطق بعض الكلمات

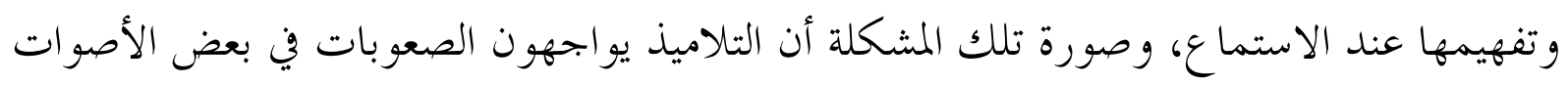

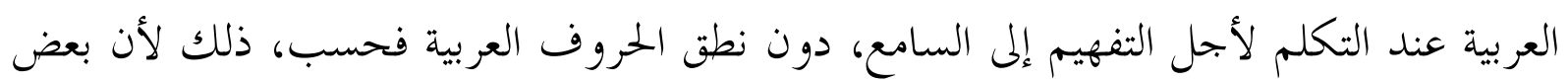

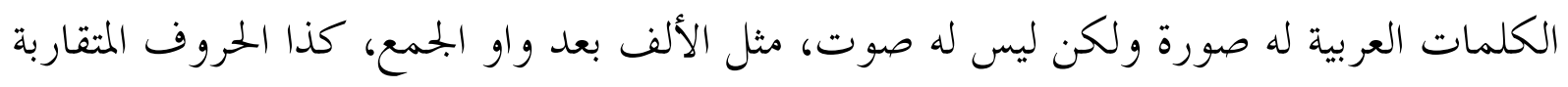

\footnotetext{
${ }^{21}$ Kuswoyo, Konsep Dasar Pembelajaran Mahārah Al-Kalam,.. hlm. 4
} 
في المخرج، فربما ينطق التلاميذ تلك الحروف نطقا غير صحيح حتى يسمع السامع خلاف مايقصده المتكلم.

تأكيدا للمقابلة السابقة، ذكر أدي رسماو ان تلميذ الفصل الثامن نطق أن الَصوات العربية عند التكلم يختلف عن نطقها عند القراءة، ذلك لأن العادة العامة في المحادثة كثرة الوقف والسكتة، وأحيانا لايفهم السامع ما نطقه المتكلم بسبب نقص الألف أو الياء أو عدم وضوح علامة التأنيث و التذكير.r

بناء على المقابلة السابقة فيمكن القول أن صعوبات الكاملام العربي جهة نطق الأصوات تنشأ من الكلمات العربية له صورت ولكن ليس له صوت، و كثرة الوقف والسكتة عند المحادثة، وعدم وضوح علامة التأنيث والتذكير عند المحادثة، و كذا وجود الشدة وتغيير الصوت الذي يؤدي إلى تغيير المعنى. ب . معوبات المفردات

ظهرت أهمية المفردات للتعبير إذلابد من معرفة عدد كبير من الكلمات المختلفة ليتمكن التلميذ من التعبير عن أفكاره، وأن كثيرا من التلاميذ الذين يعانون من صعوبات في التعلم لايعرفون العدد الكا في من المفردات بسبب نقصان المفردات، فالتلاميذ الذين لايملكون مفردات كافية، فيو اجهون الصعوبات عند إر ادة التعبير. بناء على مقابلة الباحث مع مدرس اللغة العربيت في مدرسة رياضة العلوم الثّانويّة الإسلامية باتانج هاري لامبونج الثّرقية ، يتضح من تلك المقابلة أن من صعوبات الكام العربي نقصان المفردات لدى التلاميذ، ذلك لأن التلاميذ يواجهون المشكلة عند إرادة التعبير عن أفكارهم لقلة المفردات، أو صعوبتهم في اختيار المفردات المناسبة للموضوع، ور.بما يعرفون معاني المفردات، لكن لايقدرون على استخدامها للتعبير حين يريدون التعبير عن المعاني المختلفة، مثل الأمر، أو الاستفهام، أو التعبير عن الأفعال حسب أزماها الواقعة.

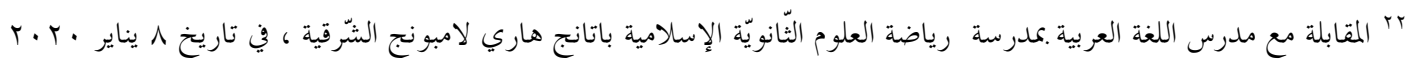

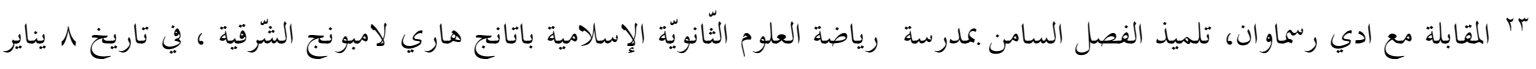

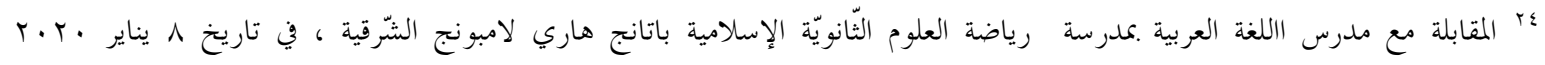


50 Abdul Halim, Masrurotul Mahmudah, Muhammad Syaifullah, dkk: Analysis of the Difficulties Learning...

بناء على المقابلة السابقة، فيمكن القول أن صعو بات الكلام العربي من جهة المفردات تنشأ

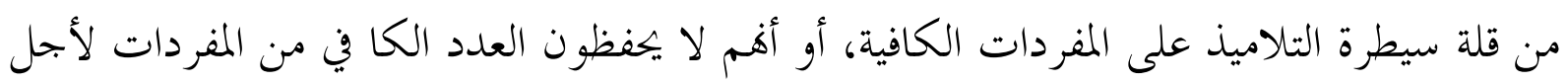

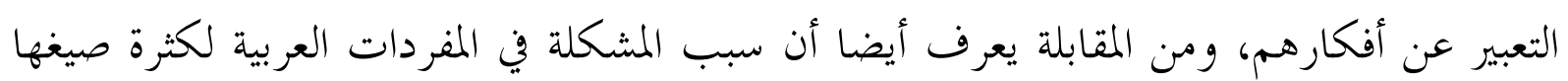

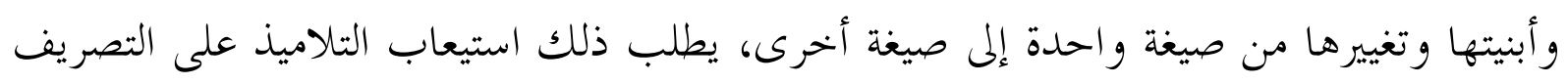

$$
\text { r. ومعرفة أحو ال الكلمة المتصرفة. }
$$

يواجه كثير من التلاميذ الذين يعانون من صعوبات الكلام العربي في تطبيق قواعد اللغة،

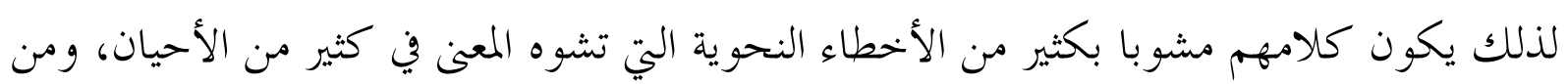

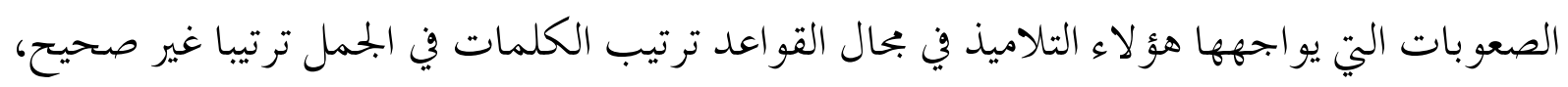

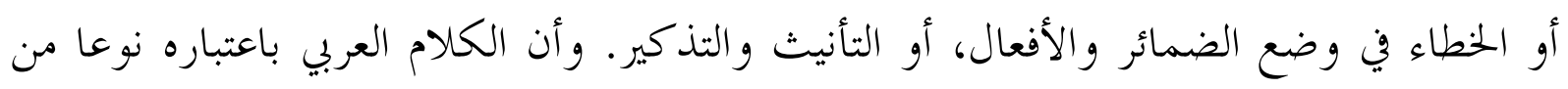

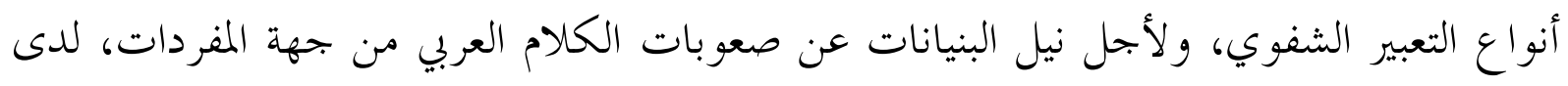

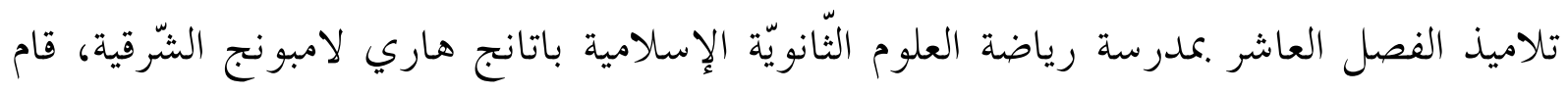
الباحث على المقابلة مع المدرس و التلاميذ كمافي الشرح التالي: بناء على مقابلة الباحث مع مدرسة اللغة العربية في مدرسة رياضة العلوم الثّانويّة الإسلامية

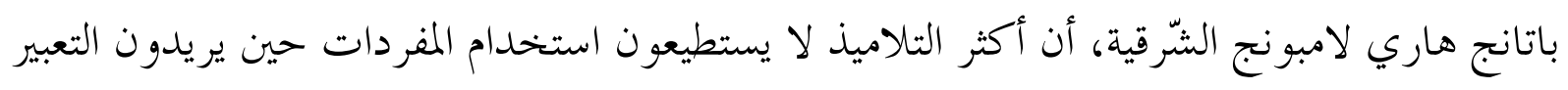
عن أفكارهم، وذلك بسبب ضعفهم في القواعد العربية، ومن الواقع، أن أكثرهم لايعرفون الجملة

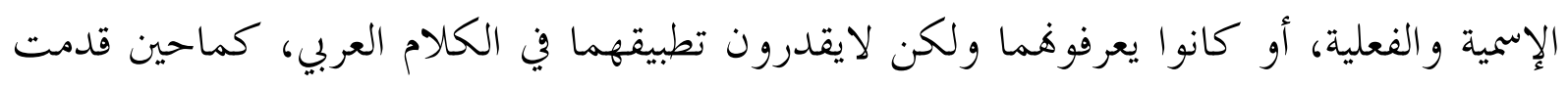
لهم المفردات ثم يطلبون على وضعهما في الكلام العربي، و كثيرا تصور التلميذ أن المعاني التي تدور

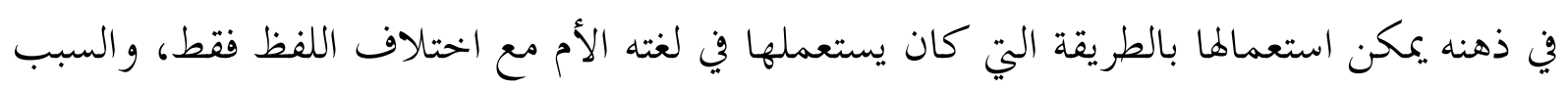
في هذح المشكلة أشد الإعتماد على الترجمة من تأثير لغته الأم وصعوبة التعبير عن المعاني العربية بالكلمات و الأساليب العربية.

وذكر ألف سفارالدّين، أحد تلاميذ الفصل الثامن "عندي صعوبات كثيرة في الكلام العربي، مثل وضع الجملة الاسمية والفعلية أوعند إرادة التعبير عن الاستفهام باللغة العربية، وربما نطق الجملة

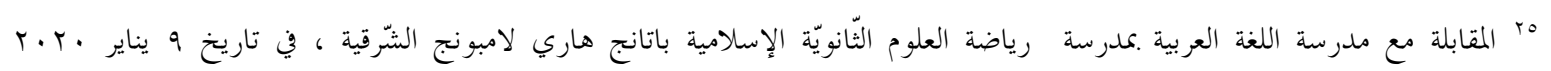


لكن لايناسب الخبر بالمبتدأ في التأنيث و التذكير، لعدم فهم القواعد، وعندي مشكلة أخري في وضع

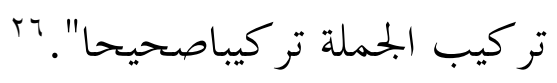

بناء على حاصلات المقابلة المذكورة، يعرف أن صورة صعوبات الكلام العربي لدى التلاميذ في صفة عامة ترجع إلى صعوبات التلاميذ في القواعد أي النحو والصرف، وضعفهم في المفردات وقلة اعتيادهم على التعبير الشفوي عن أفكارهم وشعورهم، وتطهر تلك المشكلات عند وضع الجمملة الاسمية والفعلية أوعند إرادة التعبير عن الاستفهام باللغة العربية.

$$
\text { ع. علاج صعو بات الكلام العربي }
$$

تحتاج صعو بات الكلام العربي إلى علاجها باعتبار أسباها وبالنظر إلى إمكانية تنمية مواهب

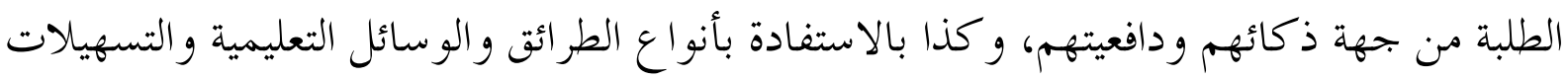
المتوفرة في المدرسة.

$$
\text { أ) علاج صعو بات الكلام العربي من جهة الأصوات العربية }
$$

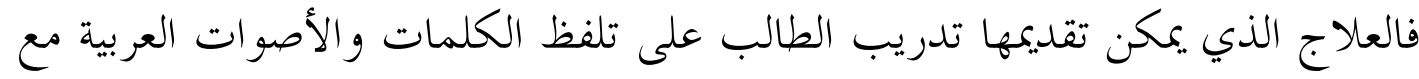
مر اعاة خصائصها مثل محارج الحروف والتنغيم وغير ذلك، لأن خطاء التلفظ ربما يؤدي إلى خطاء الفهم من قبل السامع، ولأجل نيل البيانات عن صعو بات الكلام العربي من جهة الأصوات، قابل الباحث مع مدرس اللغة العربية كما في الاقتباس التالي: تتميز هذه المدرسة بكثرة تلاميذها الذين يتعلمون القرأن في المعهد الإسلامي، فيتعلمون

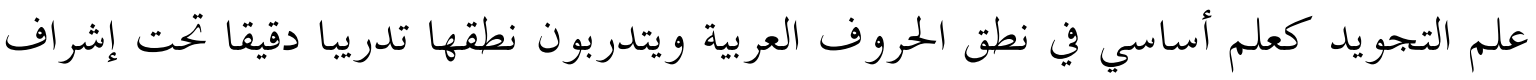

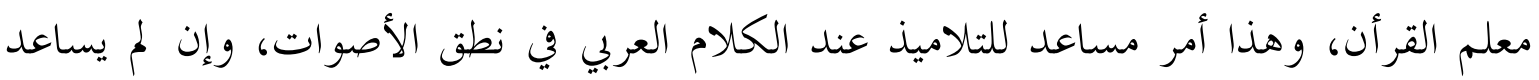

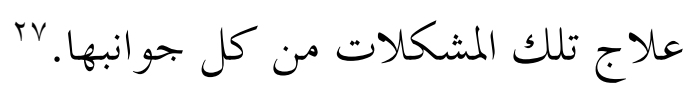

وذكرت نورمتا أوليا سافتري، تلميذة الفصل الثامن أن المدرس يؤكد صحة نطق المقال الحروف عند تطبيق الحوار، ور.بما لم يسامح التلاميذ الوقف عند نطق الكلمة في تدريب الحوار، لأجل

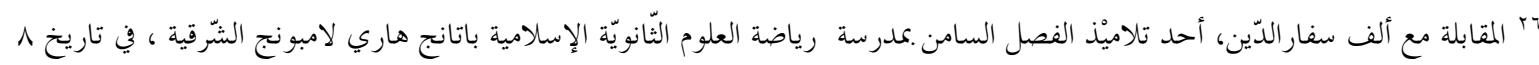

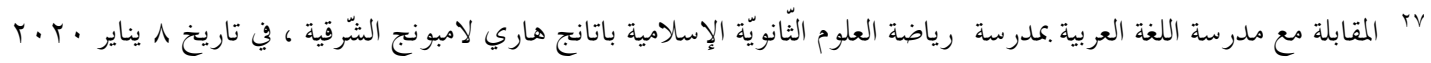


52 Abdul Halim, Masrurotul Mahmudah, Muhammad Syaifullah, dkk: Analysis of the Difficulties Learning...

وضوح الأصوات وتسهيل الإفهام للسامع، وحين نطق بعض التلاميذ نطق الحرف نطقا خطيئا،

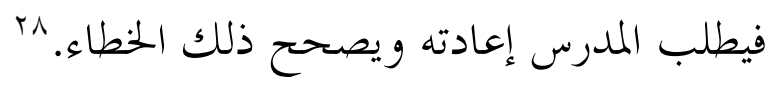
نظر إلى المقابلة المذكورة، فيمكن القول أن المحاولات لعلاج صعو بات المعات الكلام العربي من جهة نطق الأصوات هي تصحيح خطاء التلاميذ في نطق الحروف عند الحوار، ولتركيز على له وضوح الأصوات عند الحوار، وقلة المسامحة على الوقف لأجل الإفهام للسامع. ب) علاج صعوبات الكلام العربي من جهة المفردات

من المحاولات لعلاج صعو بات الكلام العربي من جهة المفردات هي كثرة التدريبات على

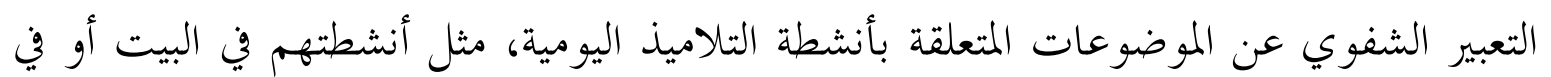
المدرسة، ومنها طلب التلاميذ على التدريبات المتكررة حول القاعدة الواحدة، فمثلا، بعد تقديم قاعدة الجملة الاسمية، فيتمرن الطلبة وضع ثلاثة النماذج أو أكثر، وبعد تمام تقديم المواد، يلزم على الطلبة قيام الواجبات المنزلية. ولنيل البيانات عن المحاولات التي نفذها المدرس لعلاج صعو بات الكلام العربي من جهة المفردات، فقام الباحث بالمقابلة مع مدرس اللغة العربية كما يلي:

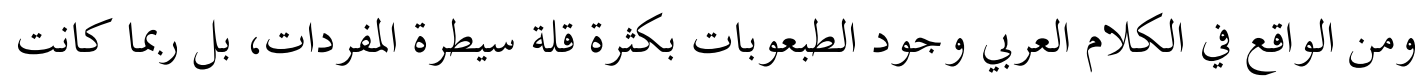
هذه المفردات أغلب الصعو بات في الكلام العربي، ولذا نحاول علاجها بكثرة استخدام المفردات في المحادثة اليومية، وإن كانت في الوقت الأن بتحري على قلة فعالة، وأيضا نعطي التلاميذ الفرصة لاختيار الموضوع في الحوار كي يطبقوه عند التطبيق داخل الفصل، وربما نلزم على التلاميذ

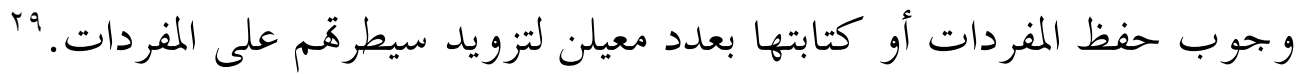

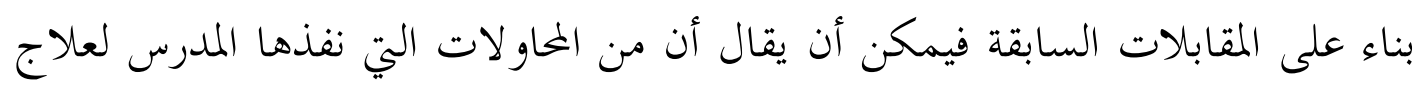
صعوبات الكلام العربي، هي خثرة التدريبات وإعطاء الواجبات الدراسية التي تتعلق بالكالام العربي، ور.ما يتيح المدرس الفرصة لدى الطلبة للتعبير عن أنشطتهم اليومية في المدرسة، ويختارون من عند أنفسهم الموضوع المناسب، يهدف ذلك تشجيعهم إلى الكلام العرب يحسب قدرهم

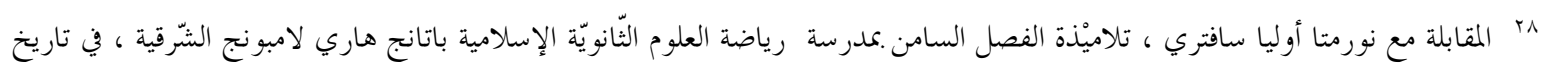
q 9

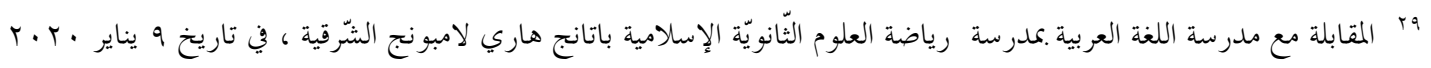


وسيطرةم على المفردات و القواعد و لا يركز المدرس حين ذلك توجيه القواعد، بل تشجيع الطلبة

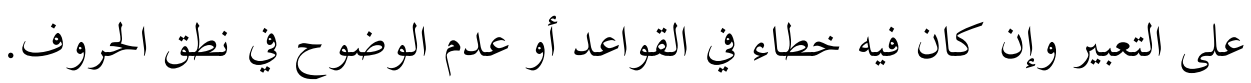
ج) علاج صعوبات الكلم العربية من جهة التركيب (القواعد والإعراب)

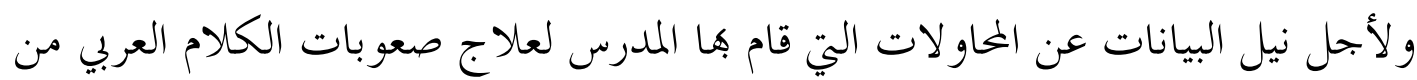
جهة القواعد، قابل البهز مع عالم مدرس اللغة العربية حيث ذكر مايلي:

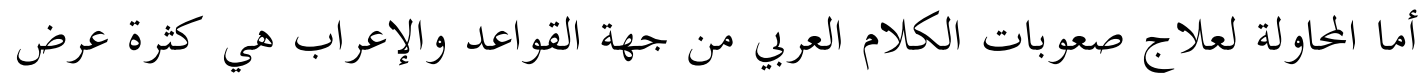

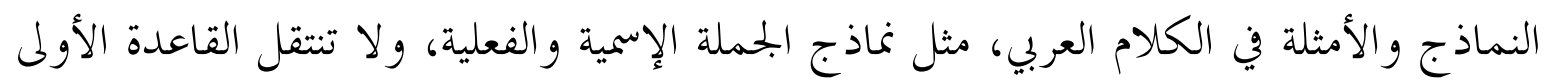
إلى القاعدة التالية حتى يقدر التلاميذ على التطبيق بعرض النماذج من رأيهم ويستطيعون على

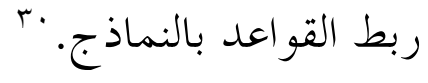

و كما ذكرت إيرديا إندراواتي، تلميذة الفصل الثامن, أن المدرس في طوال هذا الوقت

يكثر تدريب الحوار بعد تمام شرح المواد، وفي الحقيقة يؤكد المدرس التلاميذ على تطبيق المحادثة

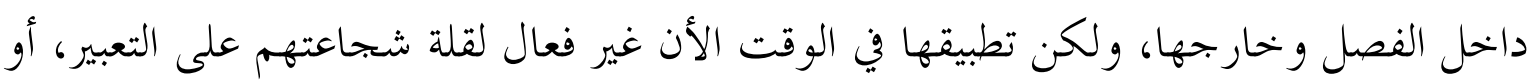

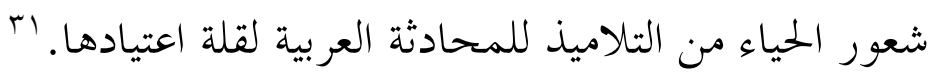

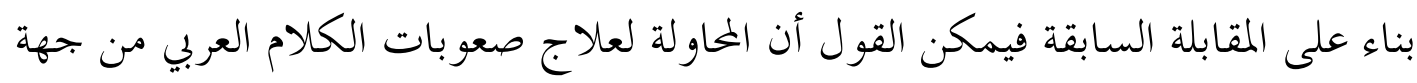
التركيب هي كثرة عرض النماذج والأمثلة في الكلام العربي وتعويد التلاميذ بالنماذج البسيطة والمتنوعة حول القاعدة الواحدة بالمفردات المألوفة وكثرة تدريب الحوار بعد تمام شرح المواد.

وبعد أن نال الباحث البيانات الختاجة من المقابلة مع عدة المصادر في مدرسة رياضة العلوم الثّانويّة الإسلامية باتانج هاري لامبونج الشّرقية، فهنا يحللها الباحث لأجل الإمكان على الاستنتاج و التفسير، و بالتالي يستطيع هذا التحليل جواب سؤ ال البحث، فيحلل الباحث تلك البيانات كما يلي:

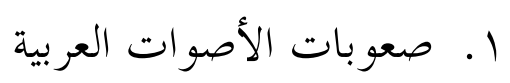

إن لكل لغة خصائص التي تخالف ها عن اللغات الأخرى، فكذلك اللغة اللعربية، فإن لها نظاما صوتيا يخالف عن اللغة الإندونسية في نطق الحروف، ولها حركات متنوعة مثل الفتحة

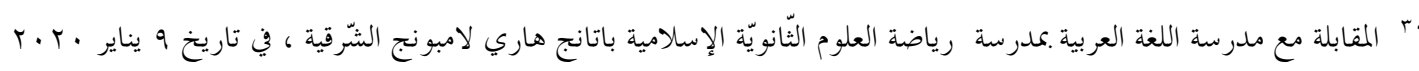

ابr إيرديا إندراواتي المقابلة مع ، تلاميْذة الفصل السامن بمدرسة رياضة العلوم الثّانيّة الإسلامية باتانج هاري لامبونج الشّرقية ، في تاريخ ه 
54 Abdul Halim, Masrurotul Mahmudah, Muhammad Syaifullah, dkk: Analysis of the Difficulties Learning...

والضمة، والحركات الطويلة والقصيرة، وكذا يخارج حروفها و كل ذلك يخالف عن اللغة

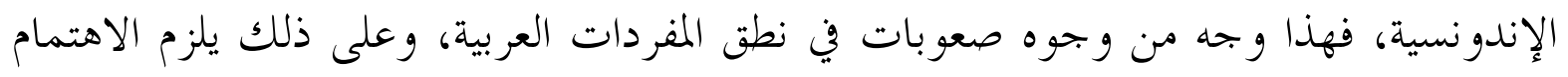

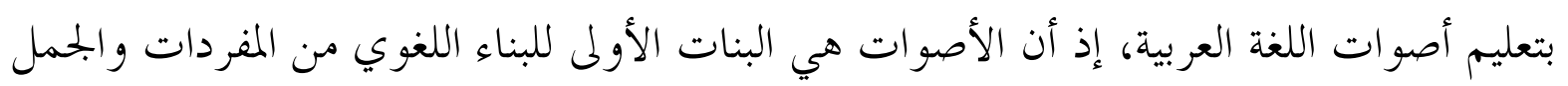

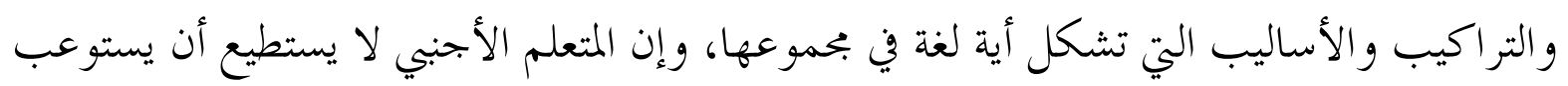
مايتعلم ويجيد نطقه بدون تعلم الأصوات. وفي الكلام العربي لايهدف نطق الحروف و الكلمات هدفا مثل هدف نطق الحروف في

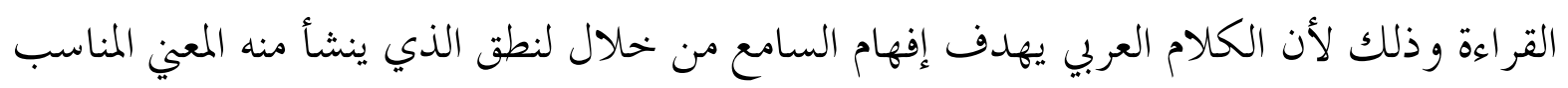

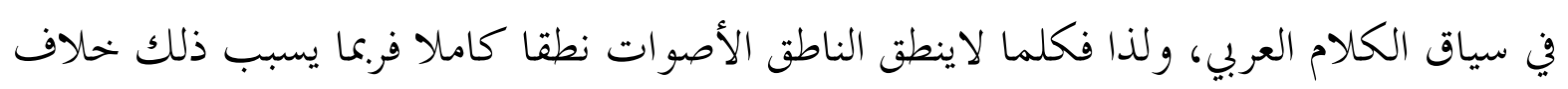
الفهم بل الخطاء في تفسير الكلمة المنطوقة. r بع بعات المفردات العربية

إن المفردات مبدأ رئيسي في الكلام العربي، وهي أول مايتوزد التلميذ لاستخدام اللغة كو سيلة الاتصال في أنواع البمالات، فهي ضرورة من ضرورات فئس الحياة، إذا لا يمكن الاستغناء عنها في جميع النشاط اللغوي، لأها عنصر رئيسي في الاتصال بين الأفراد، وهي التي تربط بين الأفكار

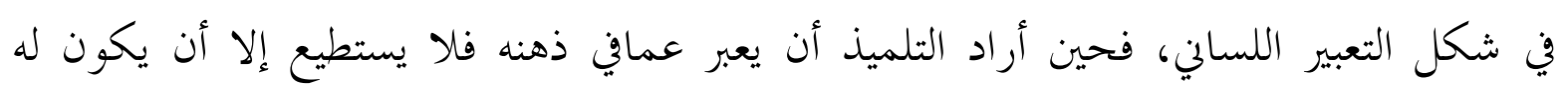

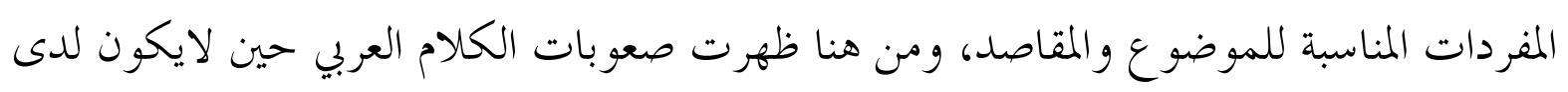
التلاميذ مفردات كافِية لأجل التعبير، وأن يقدرون على التعبير عن كل المقاصد في كل وقدئ وقت ومكان.

وظهرت صعوبات المفردات في الكلام العربي، حين لا يقدر التلاميذ على التعبير الشفوي

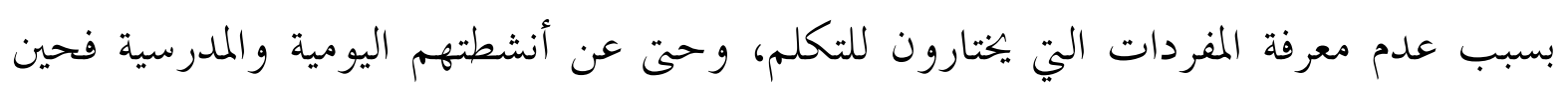

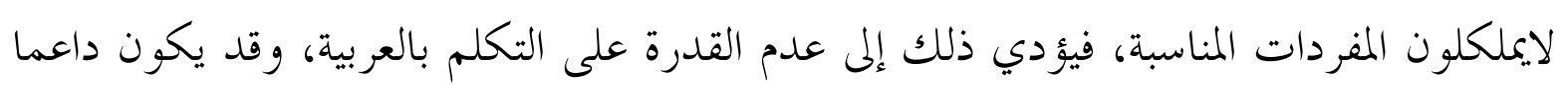
إلى قلة شجاعتهم في اللتعبير اللساني.

يرى رشدي أحمد طعيمة "ليست القضية في تعليم المفردات أن يتعلم الثلميذ نطق حروفها

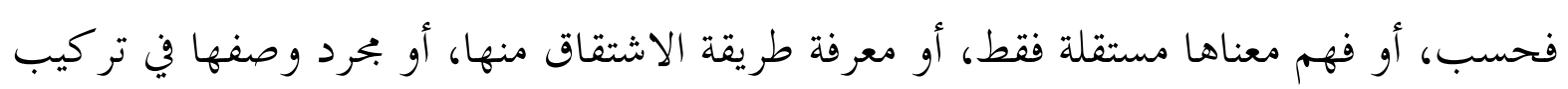


لغوي صحيح،إن معيار القدرة في تعليم المفردات هو أن يكون التلميذ قادرا على هذا كله بالإضافة

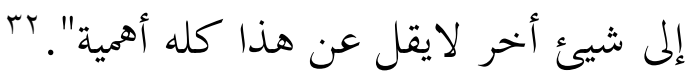

وكانت قدرة التلاميذ على استخدام المفردات عند المحادثة هي المعيار والهدف الأخير في تعليم المفردات، وذالك بتقليم المفردات المختلفة المناسبة الأغراضهم ومو اقفهم في موضوع علمعيد المحادثة حتى يتمكن لدي التلميذ أن يعبر تعيرا واضحا منظما سليما من الخطاء في التركيب. ومن أسباب مشكلات المفردات التي تؤدي إلى مشكلات الكلام العربي هي أن اللغة العربية إنسية غنية بالمتر ادفات وبعض هذه المفردات واضحة المعنى ومشهورة وبعضها غير واضح وكذا الأسماء

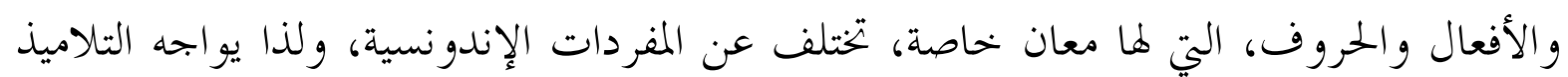
الصعوبات في الكلام العربي حين لايقدرون على تعيين نوع المفردات من الأسماء والأفعال والحروف، و كذا حين لايقدرون على معرفة المفردات من جهة ترادفها. r. صعوبات التر كيب (القواعد و الإعراب)

إن تعليم اللغة يرتبط ارتباطا وثيقا بتعليم قو اعدها، و كذ في الكلام العربي، ذلك لأن القواعد تعصم عن الخطاء عند التكلم، ولها وظيفة لعصمة أصالة اللغة عن المتعيرات المفسدة النظام اللغة ولنة

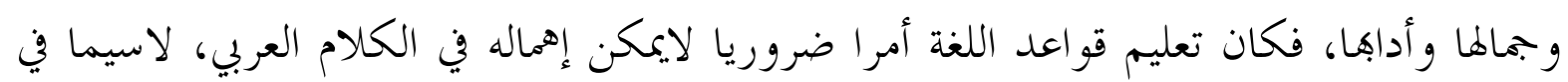
العصر الحديث الذي قد انتشرت فيه اللغة العامية التي تؤدي إلى قاون القواعد وضياعها، ولا يهتم مستخدم اللغة بصحة القواعد وخطائها. وترجع صعوبات الكلام العربي إلى ضعف القواعد والمفردات وتصنيف الأفكار وترتيبها

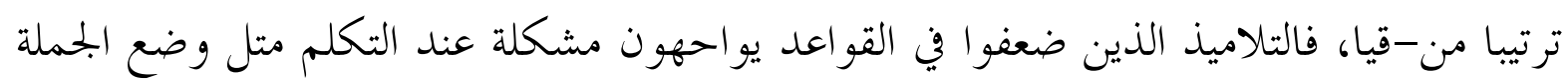

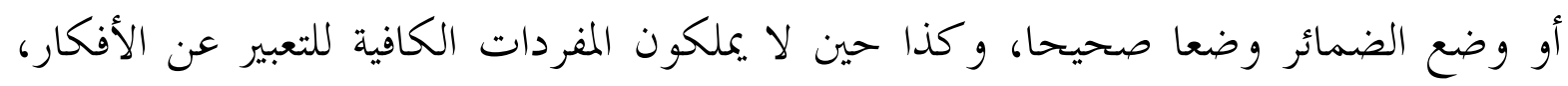
سؤدي ذلك إلى صعوبتهم في اللتعبير، ور.ما يكتبون المفردات غير المناسبة للموضوع وبعد ذلك ونك يو اجه التلاميذ صعو بات عند تصنيف الأفكار وترتيلبها ترتيبا منطقيا في شكل اللغة المكتوبة، لعدم خبر تهم في التكلم. ويهتم تعليم القواعد العربية على التلاميذ، لتزويدهم بما يعصم لساهم عن الخطاء عند

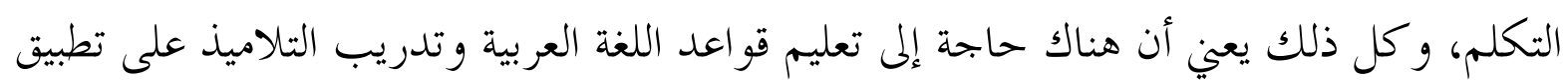


قواعدها مؤيدا بالنماذج والأمثلة المختلفة، ويستمر ذلك حتى يكون لدى التلاميذ استيعاب

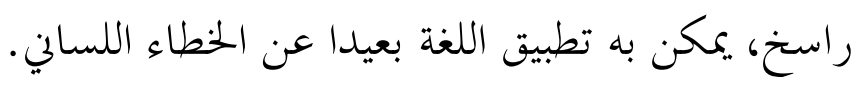
ع. علاج صعوبات الكلام العربي

يجتاج علاج صعو بات الكلام العربي إلى معرفة أسباها فيعالج المدرس بعد تحقيق المشكلات

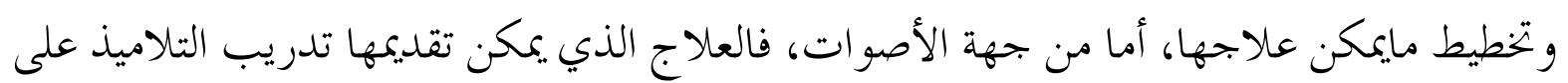
تلفظ الكلمات والأصوات العربية مع مراعاة خصائصها مثل محارج الحروف والتنغيم وغير ذلك.

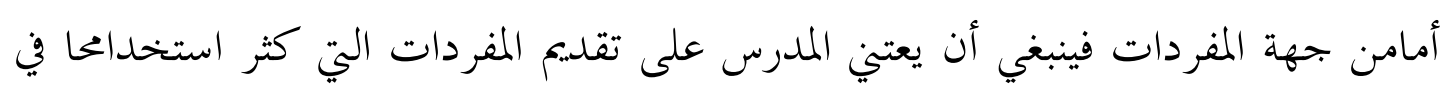

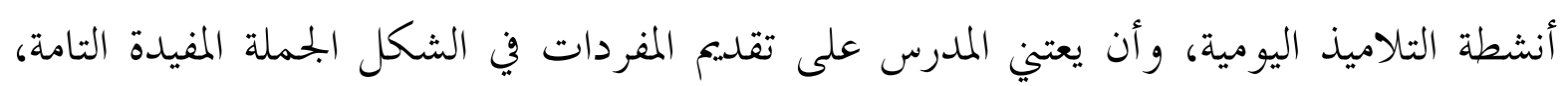

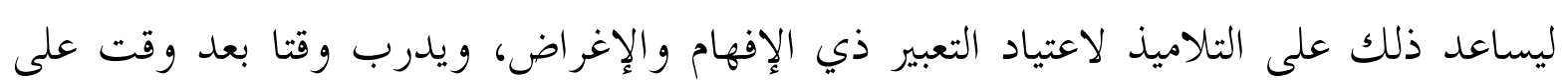
التمرن بالتعبير المفيد والجيد.

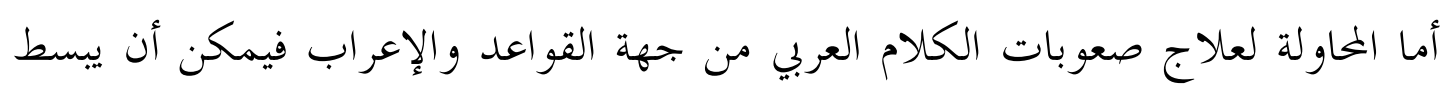

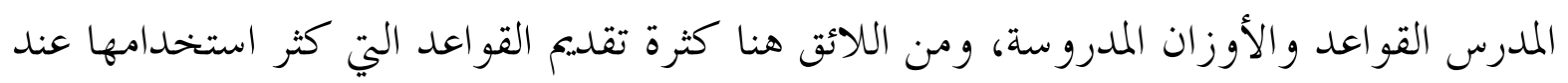

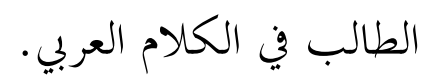

ويمكن علاج صعوبات الكلام العربي بمنح التلاميذ حريتهم ليختاروا وفق ماتمليه رغباتم الموضوعات المناسبة والألفاظ والأساليب المعبرة عنها، وتدريب التلاميذ على أشكال التعبير المختلفة

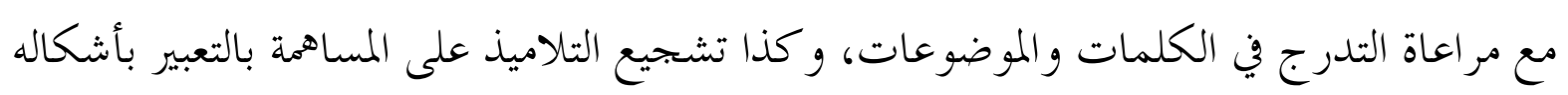
في غير خصص الدراسة، مثل المشار كة في التمثيل أو المناطرة أو الخطابة.

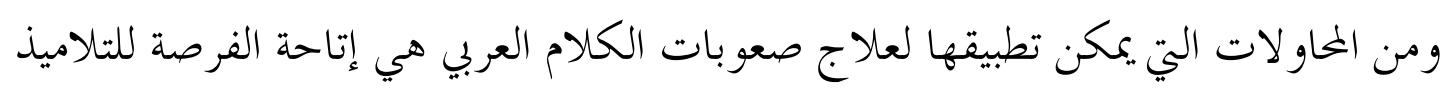

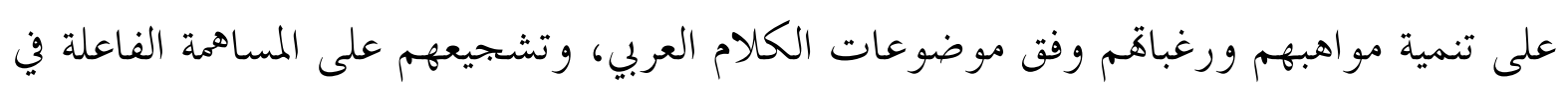

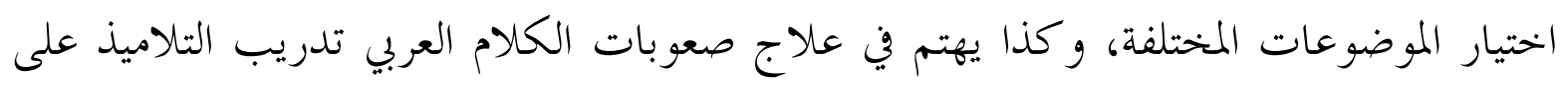
أشكال التعبير المختلفة وتعو يدهم علي استخدام المفردات التي يعرفوها في شكل التخاطب و والتحدث داخل الفصل أو خارجه. 
ووظيفة المعلين على التطوير المدخل إلى الأساليب والاستراتيجيات المصممة لحالة الطلاب

$$
\text { والبيئة التي يو اجهوها. }
$$

ترجع صعوبات تدرس الكلام العربي إلى ثلاثة الجوانب، وهي صعوبات الأصوات والمفردات

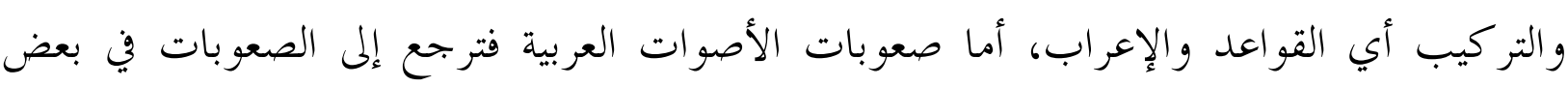

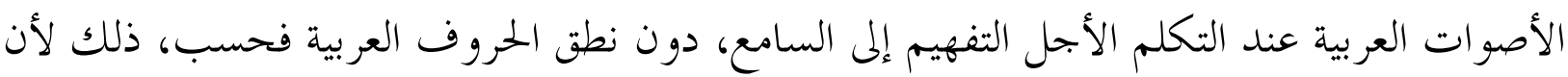
بعض الكلمات العربية له صورة ولكن ليس له صوت، فربما ينطق التلاميذ الحروف نطقا غير صحيح

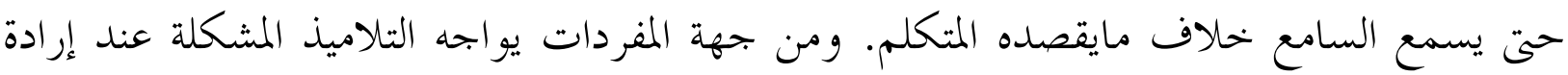
التعبير عن أفكارهم لقلة المفردات، أو صعوبتهم في اختيار المفردات المناسبة للموضوع، وروبما يعرفون معاني المفردات، لكن لايقدرون على استخدامها للتعبير حين يريدون التعبير عن المعاني المختلفة، أما من جهة التركيب فتظهر صعوبات من كون كلام التلاميذ مختلط بعدة الأخطاء في نطق الكلمات و التراكيب.

يحتاج علاج صعو بات الكلام العربي إلى معرفة أسباها فمن جهة الأصوات، فالعلاج الذي يمكن تقديمها تدريب التلاميذ على تلفّظ الكلمات والأصوات العربية مع مراعاة خصائصها مثل محارج الحروف و التنغيم، أما من جهة المفردات فينبغي أن يعتي المدرس على تقديم المفردات التي كثر استخدامها

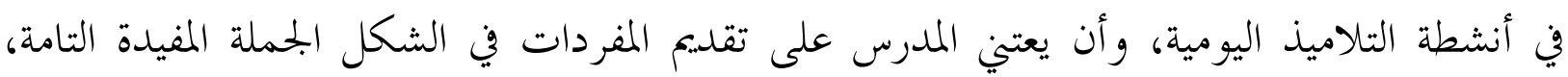
ليساعد ذلك على التلاميذ لاعتياد التعبير ذي الإفهام والإغراض، أما المحاولة لعلاج صعو بات الكئي الكلام

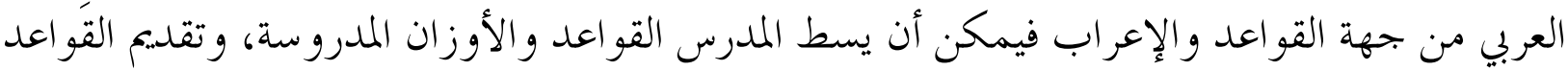

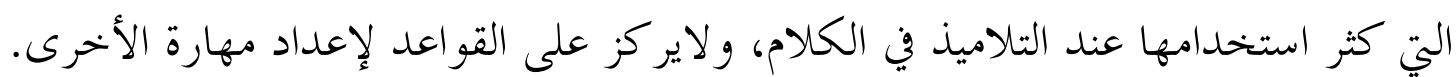

\section{Bibliografi}

Acep, Hermawan. Metodologi Pembelajaran Bahasa Arab. Bandung: PT Remaja Rosdakarya. 2014.

Ahmadi, Abu., dan Widodo Supriyono. Psikologi Belajar, cet.ke-3. Jakarta: PT Rineka Cipta. 2013.

Al-Naqah, Mahmud Kamil Wa Rusydi Ahmad Thu'aimah. Thoroiq Tadris al-Lughah al-Arobiyah

${ }^{33}$ Muhammad Syaifullah, Curriculum and Syllabus for Teaching Arabic in General Secondary Schools (Evalustion Study). IJ-ATL (International Journal of Arabic Teaching and Learning). UNUJA Probolinggo. Vol. 1 No. 1 January-Juni 2018. ISSN: 2549-4813 E-ISSN: 2549-368X. http://doi.org/10.33650/ijatl.v2i1.302 
Lii Ghairi al Nathiqina Biha. Al-Su'udiyah: Jami’ah Ummu al-Quro. 2003.

Anwar, Abd. Rahman. "Penerapan Metode Langsung Dalam Pembelajaran Bahasa Bahasa Arab", Jurnal Diwan, Makasar: Universitas Islam Negri (UIN) Alauddin Makasar, Volume 3, Nomor 1. 2017.

Aunurrahman. Belajar Dan Pembelajaran. Bandung: Alfabeta. 2012.

Azwar, Arsyad. Bahasa Arab dan Metode Pengajarannya. Yogyakarta: Pustaka Pelajar. 2010.

Hermawan, Acep. Metodologi Pembelajaran Bahasa Arab, PT Remaja Rosdakarya: Bandung. 2014.

Ifi, Erwhintiana., et al. Analisis Diagnostik Kesulitan Belajar Maharah Kalam Mahasiswa Bahasa Dan Sastra Arab 2017 Dalam Perspektif edwin R. Guthrie, HMJ Jurusan Sastra Arab Fakultas Sastra Universitas Negeri Malang, ISSN 2598-0637. 2017.

'Isa, Ahmad. Tadribat Lughawiyyah. Al-Su'udiyah: Darul Isybiliyyah wa at-Tauzi'. 2003.

Kuswoyo. Konsep Dasar Pembelajaran Mahārah Al-Kalam, An-Nuha: Sekolah Tinggi Agama Islam Nahdlatul Ulama, MadiunVol 4, No 1, Juli. 2017.

Madkur, Ali Ahmad. Tadris Funun al-Lughah al-Arobiyah. Al-Su'udiyah: Maktabatul Falah. 1994.

Mujawir, Sholahuddin. Tadrisu al-Lughah al-'Arobiyah. Al-Su'udiyah: Darul Qolam. Duna Sanah.

Munir. Perencanaan Sistem Pengajaran Bahasa Arab, Jakarta: Kencana. 2017.

Murad, Syu'id Muhammad. At-Takamuliyyah fii Ta'lim al-Lughah al-'Arobiyah. Al-Su'udiyah: Darul Lii amalun. 2002.

Rahmaini. Strategi Pembelajaran Maharah Kalam Bagi Non Arab إحياء العربية،, Medan: Fakultas Tarbiyah dan Keguruan r. السنة الأول العداد r يوليو - ديسمبير 10 ,ISSN:2442- 8353. 2015.

Sapri. Metode Pembelajaran Bahasa Arab: Antara Tradisional Dan Modern: Jurnal Pemikiran Alternatif Pendidikan, INSANIA: Fakultas Tarbiyah Purwokerto, Volume 13, Nomor 3, SepDes. 2008.

Suharsimi, Arikunto. Metode Penelitian (Suatu Pendekatan Praktis), Jakarta: Bumi Aksara. 2010.

Syaifullah, Muhammad. Curriculum and Syllabus for Teaching Arabic in General Secondary Schools (Evalustion Study). IJ-ATL (International Journal of Arabic Teaching and Learning). UNUJA Probolinggo. Vol. 2 No. 1 January-Juni 2018. ISSN: 2549-4813 E-ISSN: 2549368X. http://doi.org/10.33650/ijatl.v2i1.302. 2018.

Thu'aimah, Rusydi Ahmad. al-Maharot al-Lughawiyyah. Al-Su'udiyah: Darul Fikri. 2009.

Ulin, Nuha. Metodologi Super Efektif Pembelajaran Bahasa Arab, Jogjakarta: DIVA Press. 2012. 